\title{
Application of Information Technology in the Redesign and Implementation of Business Processes
}

\author{
Dr. G. Lyons \\ Director, I.T. Centre, U.C.G., Ireland. \\ Tel.: 353-91-750382 (Direct) \\ Fax.: 353-91-750501 \\ E-mail: Gerard.Lyons@UCG.IE
}

\begin{abstract}
From the first appearance of the term "business process reengineering (BPR)" in the literature, information technology (IT) has been viewed as the central feature of the reconfigured enterprise. As the practice of process reengineering matures, a host of software tools and enabling technologies has besieged the lucrative BPR marketplace. This paper attempts to demystify the role of IT in enterprise reengineering, and offers a taxonomy of relevant applications, as well as some lessons from practice.
\end{abstract}

In broad terms, IT has two discrete functions in process reengineering:

1. it can support the mapping, analysis and modelling aspects of BPR projects; and

2. it can provide essential communications and systems infrastructure to facilitate the integration and automation of redesigned work processes.

This paper will explore both of these application areas and provide an assessment of their contribution to BPR methodology and process realisation in practice. The paper will finally comment on the difficulties of migration to a process based IT infrastructure and the constraints imposed by legacy systems and data.

\section{Keywords}

Business process redesign, information technology, process modelling, IT architecture, legacy systems. 


\section{INTRODUCTION}

Business processes are the collections of logically linked activities which coalesce to create tangible value for a customer. As such, they represent the central nervous system of an enterprise and cut across defined organisational boundaries with a single minded focus on creating customer satisfaction in the delivery of goods or services. For most enterprises today, business processes remain an abstraction of "the way things work around here", and have no physical manifestation in terms of organisation structure, IT architecture or building design. (The central production processes of manufacturing companies are a notable exception in this respect). But, with the lure of short cycle time delivery, dramatic reductions in overhead costs, and exceptional increases in product and service quality, "business process reengineering (BPR)" (Davenport, 1990; Hammer, 1990; Hammer and Champy, 1993) has created a religious zeal among business managers world wide in search of the optimised "core processes" (Kaplan \& Murdock, 1991) that drive enterprise competitiveness.

\section{BUSINESS PROCESSES AND IT}

Business process design, or indeed redesign, represents a fundamental departure from conventional wisdom on the way the essential work of an enterprise is viewed, examined and organised. While functional bureaucracy had its place in controlling and coordinating a complex array of discrete skill sets, its rigid structure and internal preoccupation have become barriers to performance improvement in a climate of "time based competition" and "customer value". The process based enterprise should not suffer from such maladies. But, the transition from a functional organisation will create its own difficulties, as the cornerstones of structure, strategy, skill sets and information systems are undermined in favour of a new enterprise order. For some companies in the financial services sector in the US and UK, this challenge has been too great, and a simpler solution was found: they've started afresh on green field sites with totally new processes, people, structures and systems.

From its conception, BPR has been synonymous with the rational application of information and communication technologies. For its part, the IT industry in the early 1990 's desperately needed new demand drivers, especially ones that were visibly linked to business performance. BPR has already spawned a host of software tools to aid in redesign efforts and has promoted a lucrative market for enabling information technologies. The function of IT in business process redesign is thus two fold:

1. it can support the mapping, analysis and modelling aspects of BPR projects; and

2. it can provide essential communications and systems infrastructure to facilitate the integration and automation of redesigned work processes.

But, as the existing systems infrastructure is a durable component of a functionally designed business, it too must be reconfigured or replaced. The reengineering of IT architectures must, then, be an essential part of BPR initiatives. 


\section{BUSINESS PROCESS ANALYSIS AND DESIGN}

\subsection{Redesign methodology}

During the past four years, various attempts at defining "BPR methodology" have appeared in the technical literature and at public business seminars. These methodologies typically emanate from one of the following two sources:

1. large consulting groups who have restructured their "performance improvement" products as cook book guides to BPR projects; or

2. academic systems analysts, software engineers and industrial engineering researchers, exploring new applications for their cherished modelling techniques.

Regardless of parentage, both of the resulting approaches have technical merit. But in application terms, the consulting methodologies come closer to the spectrum of needs of BPR practitioners.

The BPR project is primarily an holistic and radical performance improvement intervention. It carries responsibility for assessing and redesigning the full array of enterprise components (Waterman, et al, 1980), although centred on the work process and IT dimensions of the organisational diamond (Scott Morton, 1991). The organisational development (OD) method, applied by some practitioners, supported by the modelling techniques of IT and industrial engineering, collectively provide the breadth of understanding and rigorous analytical capability needed for effective process redesign.

In broad terms, the BPR project traverses four discrete phases:

Phase 1 Process identification, mapping and diagnosis;

Phase 2 Process baseline measurement;

Phase 3 Process benchmarking; and

Phase 4 New process design.

Alternative approaches are favoured by some practitioners, most notably the radical, "clean sheet" method, followed by early disciples of Hammer (1990), which completely ignores existing process configurations, and proceeds directly to the creation of a "no constraints" vision of the ideal process, as conducted in Phase 4 above. The difficulties encountered in such approaches are reflected in a report published last year by Hammer's own company, CSC Index (1994), which reports on a survey of over 600 US and European corporations. The report highlights poor success rates for BPR projects (with over $67 \%$ providing zero or marginal results) conducted by these corporations, and lists the most commonly found difficulties with reengineering, the top two of which were:

1. Getting the information systems and technology infrastructure in place; and

2. Dealing with fear and anxiety throughout the organisation.

The phased approach suggested above is based on the author's own practical experience of large scale BPR in a range of industries, and has parallels in other systematic methods found in consulting practice (Kaplan \& Murdock, 1991; Johansson et al., 1993). This approach comes close to the OD model of change management (Cummings and Huse, 
1989) and pragmatically addresses the difficulties inherent in implementing radical process improvements which are not grounded in the organisation's own perception and experience of "reality". Thus, the real structural and behavioural impediments to process improvement are uncovered, and personal (as well as organisational) fear and resistance are confronted openly. The rôle of the BPR practitioner in this case is to:

- develop a detailed understanding of the current business process, its performance levels and limitations;

- create a tangible and realisable model of the ideal, simplified business process, together with proof of its performance capabilities; and

- stimulate the climate for organisational change, within which transition to the new process design is likely to succeed.

\subsection{BPR project support tools}

A host of IT support tools are now available to aid the BPR project team. For the most part, these are based on established techniques, which have been applied successfully in the analysis and design of information systems in both commercial and manufacturing settings for a number of years. Table 1 presents a summary of the tools relevant to each phase of the BPR project, following the methodological framework outlined.

Discussion of each of these techniques is beyond the scope of this short paper. However, it is clear that a variety of modelling and analytical approaches are available to support process analysis and redesign. Within the past four years, a host of automated tools have been developed, or "repackaged", to enable the application of these techniques in BPR studies. These range from the simplest of graphics applications, which support process mapping (usually IDEF or process block diagramming), to integrated tool sets capable of: mapping, spreadsheet based evaluation, simulation, and even code generation.

A study of over 40 software tools which offer BPR features, conducted during the past year, suggests that most of the available tools are based on enhancements to software developed earlier for other, albeit related, purposes, including: software engineering, workflow modelling, manufacturing simulation, and general graphics. Consequently, they have not been designed for a particular methodology, nor do they support all phases of BPR projects. It is difficult to generalise about current BPR tools, as they represent such a wide range of functionality and cost. But, while most provide process mapping features, the more basic packages are limited to single level analysis and do not allow multi level "explosion" (or levelling) of the processes being analysed. Only a few are capable of dynamic simulation and evaluation, and code generation is restricted to the top end of the cost/functionality spectrum. Tool integration is also a weakness, and only the more sophisticated proprietary packages offer full integration of mapping, simulation and analysis functions. However, a number of the simpler graphical packages are now supporting DDE linkages to common spreadsheet software, to enable activity based analysis and process measurement. 
Table 1. IT as a process reengineering project support tool

\begin{tabular}{|c|c|c|}
\hline Project Phase & IT Support Rôle & Tools \\
\hline $\begin{array}{l}\text { 1. Mapping and } \\
\text { diagnosis }\end{array}$ & $\begin{array}{l}\text { Process capture and } \\
\text { appraisal }\end{array}$ & $\begin{array}{l}\text { - Data flow diagrams } \\
\text { - IDEF models } \\
\text { - Role Activity diagrams } \\
\text { - Work Study process } \\
\text { - flow diagrams } \\
\text { - IS flowcharting } \\
\text { - Functional entity diags. } \\
\text { - Soft systems methods }\end{array}$ \\
\hline 2. Baseline measurement & Process evaluation & $\begin{array}{l}\text { - Activity based costing } \\
\text { - Value added flow } \\
\text { analysis } \\
\text { - Shop floor data collxn. } \\
\text { - Spreadsheets }\end{array}$ \\
\hline 3. Process benchmarking & Information retrieval & $\begin{array}{l}\text { Benchmarking } \\
\text { databases } \\
\text { - Library info. services }\end{array}$ \\
\hline 4. Process design & $\begin{array}{l}\text { Process description and } \\
\text { development }\end{array}$ & $\begin{array}{l}\text { - Mapping tools as in } 1 . \\
\text { - Simulation } \\
\text { - Workflow modelling } \\
\text { - Code and schema } \\
\text { generation }\end{array}$ \\
\hline $\begin{array}{l}\text { BPR Project } \\
\text { management }\end{array}$ & Coordination and control & $\begin{array}{l}\text { - GANTT, PERT, CPM } \\
\text { - PM software }\end{array}$ \\
\hline
\end{tabular}

More broadly, the available tools reflect a poor understanding of the practical needs of BPR teams, whose members are drawn primarily from Business functions and have little experience of IT terminology, techniques and concepts, and consequently find sophisticated tools inaccessible and highly redundant. Like the early CASE tools, upon which many BPR products are now based, these early packages:

- offer poor coverage of the full BPR project cycle;

- lack transparent tool to tool integration (although several support DDE linkages);

- provide single user support and don't allow BPR teams to work together;

- offer poor GUI interfaces;

- are difficult to master quickly for the novice process designer, and entail a lengthy learning curve.

While the development of fully automated BPR support environments remains technically challenging, there is a danger that, once again, IT specialists will become embraced by technical elegance rather than application value. The limited success to date in the application of advanced CASE technology, to the improvement of the software development process, should serve as a timely reminder that process redesign is primarily a group learning activity. While fully automated solutions provide discipline and precision, 
and go some way to identifying optimal solutions, they rely too heavily on the individual designer's breadth of experience and business understanding. In practice, this has proven to be a poor substitute for less automated, but more "involving" approaches to process redesign, software development (such as Joint Application Development - JAD), and indeed hardware product design.

In short, automated analysis and modelling tools perform useful point solutions in the appraisal and redesign of business processes. The tools are capable of removing much of the drudgery from process mapping and evaluation, and support more sophisticated analyses and higher standard presentation. However, these are only valuable when used in support of a systematic and challenging consulting methodology, where innovation and willingness to explore new "ways of working", at high levels of abstraction, are more important than model precision.

\subsection{Analysis and design of process based systems}

Apart from exploring the processes themselves, the specification and development of a software infrastructure needed to implement the new process designs is an essential product of the BPR project. Viewed from this perspective, the automated modelling tools discussed above perform a more central function -- that of translating high level process abstractions into tangible specifications of realisable software modules.

Information Systems (IS) practitioners argue that conventional approaches to systems analysis and design are built on the modelling of enterprise processes, and that BPR does not challenge the underlying principles of software engineering. This view is misguided in a number of respects. Conventional software engineering is based on the "stepwise refinement" of high level abstractions of an enterprise's procedures and information needs, and is achieved through:

1. the functional decomposition of high level statements of procedure, until detailed definitions of functionality can be specified as software modules; and

2. data modelling and analysis, of a high level interpretation of an enterprise's subject areas, or data "entities", until relational data structures can be specified.

However, the "processes" examined by the software engineers are the defined activities performed within the boundaries of conventional organisational functions, for which IS applications are being developed.

Established software engineering approaches to enterprise level modelling and IS planning take existing organisational structures and functions as a "given" (Martin, 1982 \& 1989; Finkelstein, 1989) The Information Engineer is thus not empowered to question existing organisational structures and procedures, as is required in the analysis of horizontal business process information flows. Clearly then, the term "process" has a different meaning in Information and Software Engineering than it has for BPR practitioners, where business processes ignore the existence of today's functional and business areas. 
Thus, while Software Engineering gave birth to the modelling techniques found today in BPR, application of these within the context of its traditional IT methodologies will not yield business process based solutions and systems. Yet, software engineering tools and concepts, such as Data Flow Diagrams, IDEF modelling, Levelling, etc., can be used effectively in process redesign, as discussed earlier. What is called for, then, is a realignment of the "process" dimension of Software Engineering and the process models yielded by BPR. This realignment should be a prerequisite for the identification of systems' boundaries, early in the application development work, and should produce high level conceptual models of the enterprise (both process and data models) which reflect the process based enterprise orientation.

\section{BUSINESS PROCESS ENACTMENT}

\subsection{Enabling information technology}

Information technologies have been deployed in the service of business for over three decades. In recent years, developments in both telecommunications and computer technologies have seen an unprecedented rate of progress, as well as a convergence to yield new demand drivers and application potential. Yet, despite the enormous investment in information and telecommunications technologies throughout the 1970's and 1980's, there has been little tangible result in terms of observable economic productivity (Drucker, 1991), at least not before the emergence of BPR.

That IT can fundamentally alter the way business works, indeed the way entire industries are organised, is well argued in an authoritative text on this topic by Peter Keen (1991), and was studied at length through the MIT Management in the 1990's research programme (Scott Morton, 1991). The current BPR phenomenon owes much of its early momentum to this recognition, and to the related need to derive visible return from investment in IT, following a prolonged period of doubtful benefits and growing disenchantment with the technology.

Perhaps fortuitously, the business need to re-think core processes in response to competitive factors has coincided with the commercial maturity of a powerful array of advanced information and communication technologies. There is every likelihood that the BPR momentum will, thus, be maintained and organisational transformation will give rise to significant improvements in business performance through the application of enabling IT.

Table 2 presents a summary of the information technologies which are currently available as infrastructure components for the process based enterprise, and illustrates the principal business process requirements which these address. 
Table 2. IT as a process enactment technology

\begin{tabular}{ll}
\hline \multicolumn{1}{c}{ Process Requirement } & IT Enabling Technologies \\
\hline Process integration \& communication & - LAN, WAN, Telecomms., EDI, \\
& EFTPOS, etc. \\
Process co-ordination \& control & - Workflow, process scheduling, etc. \\
Front-end data capture \& validation & - Imaging, ATM, Minitel, SFDC, lap-top \\
Integrated work support & - Workflow, Client-Server, Imaging \\
Information storage \& access & - Database and query tools \\
Documentation \& document mgmt. & - WP, DT publishing, Imaging \\
Process work support & - Expert systems, Client-based applicns. \\
Process systems development & - CASE, IPSE, RAD, Prototyping, O-O \\
\hline
\end{tabular}

\subsection{Implementing IT enabled process re-design}

It is evident that the BPR practitioner has a well equipped arsenal of enabling information technologies to support the design phase of radically new business processes. However, new process designs seldom fail due to lack of imagination and technology opportunities. But, the implementation of these technologies has been the single greatest impediment to process realisation in BPR practice to date (CSC Index, 1994). And, unless the implementation difficulties highlighted here can be overcome, IT based process redesign is in danger of becoming yet another "technology swallow hole."

Invariably, BPR projects create a huge and characteristically different set of demands on, already over-burdened, IT functions. Wishing to respond enthusiastically, these functions find themselves with an insurmountable number of additional "system change" requests, major development plans, platform migration strategies, and data integrity problems -- all on top of the daily requirement to keep the current IT platform running smoothly. With their ability to deliver new systems on time and within budget already in doubt, the IT function often becomes the principal bottleneck to enactment of redesigned business processes. Frequently, the skills of internal IT people are more relevant to obsolete technologies; there is a culture of delivering new systems in years, rather than weeks; and the application of advanced CASE techniques to improve the development process has done little to help. Viewed as a set of business processes itself, the IT function appears to be in the greatest need of redesign.

An alternative solution is to outsource the development of new process based systems, or purchase industry proven applications which meet the needs of the new process designs. While this might appear to overcome the failings of internal IT functions, the solution is far from ideal. In many cases, the redesigned processes are so new, or unique, that external IT systems developers face the same design uncertainties as internal groups. Costs are high to begin with, and the popular press has reported several high profile court cases involving projects which have run significantly over budget and delivery date. Where 
"packaged" solutions are available, these typically impose their own process designs, as these have been developed as generic solutions for a wide marketplace. These purchased processes may not support all the requirements of the idealised new process design, and internal customisation may be inevitable.

In many situations, BPR endeavours will render the entire current systems infrastructure redundant or flawed. An enterprise's information systems, like its processes, grow organically as the immediate needs of the business change. After many years, these systems have acquired a thick covering of "barnacles" -- patches to the core systems to accommodate variations in procedures, product designs, etc., as the business evolves. While not meeting high standards of architectural design, these patched systems work, keep the business running, and embrace a wealth of knowledge developed by the business over many years. Apart from the enormous costs involved in replacing the entire systems infrastructure, there are risks associated with losing much of the "hidden intelligence" of the business, currently coded in legacy systems. In most cases, then, the enterprise will not be able to afford the luxury of an overnight conversion to new process based systems, and legacy systems will need to be maintained as new applications are developed and installed.

The migration to new hardware platforms, database technology and process based applications, thus, remains one of the principal challenges facing the enterprise as it attempts to enact redesigned business processes. The IT infrastructure may be the most difficult organisational component to change, whereas structure, performance appraisal systems and other seemingly intractable issues, can be addressed in a shorter time frame. Implementation planning of BPR must, then, recognise the centrality of IT architectures and migration schedules to the delivery of redesigned business processes. Solutions must be found which will not impair the achievement of greatly improved performance results while new technologies and applications are being assimilated. These temporary "transition solutions" may be paper based, or low technology patches to existing systems, and might well be part of a well planned migration strategy. The "surround approach", discussed by Heygate (1993), is a feasible alternative, which preserves the integrity of legacy systems while building new process functionality and user interfaces "around" the existing infrastructure.

\section{CONCLUSIONS}

Business process redesign can produce enormous improvements in operational performance of the enterprise through the deliberate design and creation of organisational structures, systems and core work activities, as distinct from evolving these as needs dictate. As an holistic and radical performance improvement intervention, BPR brings together the consulting and organisational skills of organisational development and the analytical techniques of IT. Software tools, based on IT and industrial engineering methods, can play an important support rôle in BPR projects. While the sophistication of these tools is developing rapidly, currently available products remain technologically immature. 
A more important issue for the application of IT in BPR is the enactment of redesigned processes in new software and hardware applications. In this respect, IT has been an impediment to early realisation of BPR benefits, due to the difficulties associated with software development, inappropriate skills, business reliance on legacy systems, and platform migration. These issues must be addressed in BPR implementation planning, if the intentions and efforts of enterprise process redesign are not to be discredited before they've had a chance to deliver results.

\section{REFERENCES}

CSC Index. 1994. State of Reengineering Report. Pub. CSC Index.

Cummings, T.G. and Huse E.F. (1989) Organization Development and Change 4th edn. West Publ. Co., St. Paul, Mn.

Davenport, T.H. and Short, J.E. (1990) The new industrial engineering: information technology and business process re-design. Sloan Management Review. Summer 1990. Vo. 31, No. 4.

Drucker, P. (1991) The new productivity challenge. Harvard Business Review, Nov.-Dec.

Finkelstein, C. (1989) An Introduction to Information Engineering. Addison-Wesley Publ. Co., Wockingham, England.

Hammer, M. (1990) Reengineering work: don't automate, obliterate. Harvard Business Review. .

Hammer, M. and Champy, J. (1993) Reengineering the Corporation: A Manifesto for Business Revolution. Harper Collins Pubs., Inc.

Heygate, R. Accelerating the payback from information technology: the "surround" approach. In: Managing Change to Get Results. McKinsey \& Co. Inc., (1993).

Johansson, H.J., McHugh, P. , Pendlebury, A.J. and Wheeler, W.A (1993) Business Process Reengineering: Breakpoint strategies for market dominance. John Wiley \& Sons, New York.

Kaplan, R.B., and Murdock, L. (1991) Core process redesign.The McKinsey Quarterly, No. 2.

Keen, P. (1991) Shaping the Future - business design through information technology. Harvard Business School Press, Boston, Mass.

Martin, J. (1982) Strategic Data Planning Methodologies. Prentice Hall, N.J.

Martin, J. (1989-90) Information Engineering (3 volumes) Prentice Hall, N.J.

Scott Morton, M. (ed. 1991) The Corporation of the 1990's - Information technology and organisational transformation. Oxford Uni. Press, New York.

Waterman, R.H., Peters, T.J.and Phillips, J.R. (1980) Structure is not organization. Business Horizons. 


\section{BIOGRAPHY}

Gerard Lyons is Director of the Information Technology Centre, at University College Galway, where he is responsible for academic programmes and applied research in Information Technology. He joined UCG in 1991, having previously worked in manufacturing, with Digital Equip. Corporn., where he managed groups in the Information Systems, IT Strategy, Logistics Process Design and R\&D areas. Gerard's early career was spent with a national research institute, where he specialised in systems analysis and financial modelling. He has published widely in management and technical journals, has co-authored a text on manufacturing systems, and is a frequent speaker at international conferences.

In addition to his academic position, Gerard is an independent Management and IT Consultant, specialising in BPR, Supply Chain Management, IT and Organisation Design, and IT Strategy Planning. His clients are large companies in the Service and Manufacturing and sectors, and his work with these is at the leading edge of BPR practice in Europe. 